\title{
PARAÍSO INHABITADO DE ANA MARÍA MATUTE: UN SINGULAR ESTILO TARDÍO DESDE LA INFANCIA COMO ORIGEN
}

\author{
Yannick Llored \\ Université de Lorraine \\ yannick.1lored@univ-lorraine.fr
}

\begin{abstract}
RESUMEN: La última novela publicada en vida por Ana María Matute, Paraíso inhabitado (2008), profundiza en los elementos cruciales del mundo de la infancia, tales como la importancia de la imaginación, el descubrimiento de la propia identidad y la progresiva confrontación con el mundo, a partir de una doble perspectiva: la de la niña Adriana y la de la voz de la narradora ya mayor, que vuelve sobre los recuerdos más entrañables de su niñez. Esta doble perspectiva, que acentúa una obsesión por el tiempo en la escritura, muestra cómo la instancia autorial va arrojando luz sobre su relación íntima con la creación literaria, es decir, también con su propia genealogía como escritora, sumergiéndose en la potencia de revelación, de desgarramiento y de invención inherentes a las experiencias interiores más perennes de la niñez, y ello al enfrentarse a la vez a la cuestión ineludible del fin, tanto de la vida como de la obra literaria en su conjunto.
\end{abstract}

PALABRAS CLAVE: Ana María Matute, Paraiso inhabitado, infancia, memoria, tiempo, poética, estilo tardio, muerte.

\section{UNINHABITED PARADISE BY ANA MARÍA MATUTE: A SINGULAR LATE STYLE FROM CHILDHOOD AS ORIGIN}

ABSTRACT: The last novel published by Ana Maria Matute, Paraíso inhabitado (2008), delves into the crucial elements of the world of childhood, such as the importance of imagination, the discovery of one's own identity and the progressive confrontation with the world, from a double perspective: that of the Adriana girl and that of the voice of the older narrator, who returns to the most intimate memories of her childhood. This double perspective, which accentuates an obsession with time in writing, shows how the authorial authority sheds light on its intimate relationship with literary creation, that is, also with its 
own genealogy as a writer, immersing itself in the power of revelation, tearing and invention inherent in the most perennial inner experiences of childhood, and this by confronting at the same time the unavoidable question of the end, both in life and in a literary work.

KEYWORDS: Ana María Matute, Paraíso inhabitado, childhood, memory, time, poetry, late style, death.

\section{PARAÍSO INHABITADO D'ANA MARÍA MATUTE: UN STYLE TARDIF SINGULIER À PARTIR DE L'ENFANCE COMME ORIGINE}

RÉSUMÉ: Le dernier roman publié de son vivant par Ana María Matute, Paraíso inhabitado (2008), pénètre au plus profond des éléments cruciaux du monde de l'enfance, tels que l'importance de l'imagination, la découverte de l'identité personnelle et la confrontation progressive avec le monde, à partir d'une double perspective: celle de la fillette Adriana et celle de la narratrice déjà âgée qui revient sur les souvenirs les plus chers de son enfance. Cette double perspective, qui accentue une obsession à l'égard du temps dans l'écriture, montre comment l'instance auctoriale met progressivement en lumière sa relation intime avec la création littéraire, c'est-à-dire aussi avec sa propre généalogie comme écrivaine, et ce, en s'immergeant dans la puissance de révélation, de déchirement et d'invention inhérentes aux expériences intérieures les plus pérennes de l'enfance, tout en affrontant la question inévitable de la fin, aussi bien de la vie que de l'ensemble de l'œuvre littéraire.

MOTS CLÉS: Ana María Matute, Paraiso inhabitado, enfance, mémoire, temps, poétique, style tardif, mort.

Recibido: 03/12/2018. Aceptado: 13/05/2019

Quizá el lenguaje poético sea, en el fondo, el más próximo a mi concepto personal de lo que es la escritura: el uso de la palabra para perseguir y desentrañar el envés del lenguaje, el revés del tejido lingüístico.

Ana María Matute, En el bosque (discurso pronunciado en la RAE, enero de 1998) 
Cuando Ana María Matute (1925-2014) publica Paraíso inhabitado (2008), la escritora ampliamente reconocida ${ }^{1}$ tiene ya 83 años y afronta, pues, la última fase de su vida reuniendo en la novela el fin próximo de la creación literaria iniciada con precocidad a finales de los años 1940- y el de su propia trayectoria vital $^{2}$. Además de ahondar, mediante una escritura especular y reflexiva, en algunos temas clave que recorren casi toda su producción literaria -tales como, entre otros, la infancia, el caínismo, la búsqueda de la propia identidad y los deseos de la imaginación ${ }^{3}$-, Paraíso inhabitado es una novela sorprendente y singular que crea sus propias formas de expresión y de invención literaria. En efecto, su singularidad reside ante todo en la capacidad de la escritora para sondear las experiencias primigenias y originales -constitutivas de la infancia ${ }^{4}$ de cuanto iba a forjar su profunda subjetividad moral, imaginativa, afectiva e incluso existencial, y ello a la luz de la exploración de un proceso expansivo de desposesión, de desvanecimiento y, finalmente, de muerte.

De ahí la naturaleza algo híbrida de la ficción autobiográfica interiorizada que es, en realidad, la última novela publicada en vida por Ana María Matute, la cual deja muy atrás en su lenguaje literario ciertos códigos y recursos de la novela de formación. De hecho, la poeticidad de la escritura profundiza no tanto en los ámbitos creativos ligados a las nociones de "balance" y "testamento" literarios, sino más bien en el universo propio de los nódulos-reductos de la autorrevelación del yo en lo más hondo de la íntima reciprocidad entre la experiencia creadora -en un sentido amplio- y la puesta a prueba de lo vivido en la infancia. Es interesante observar, por otra parte, ciertos elementos literarios y tonalidades de las voces narrativas bastante comunes entre esta novela de Ana María Matute y la penúltima que publicó Juan Goytisolo, es decir, Telón de boca (2003), en la que también el escritor se va despidiendo de su obra literaria y del mundo al esculpir una profunda poética del olvido y una moral de lo esencial ${ }^{5}$.

1. Ver Jesús Cañete Ochoa et al. (2011: 25-55).

2. La última obra publicada de Ana María Matute es su novela póstuma y sin duda inacabada, Demonios familiares (2014).

3. Estos temas y algunos rasgos estilísticos más constantes en la producción literaria de Ana María Matute ya se verifican en su novela Luciérnagas, que la autora escribió a finales de los años 1940. Esta novela quedó inédita hasta 1955 a causa de la censura franquista y se publicó entonces con el título En esta tierra. En 1993, tras una extensa revisión, Ana María Matute publicó finalmente la primitiva versión de la novela recuperando el título inicial, Luciérnagas.

4. Ver el libro de entrevistas de Marie-Lise Gazarian-Gautier a Ana María Matute en el cual la escritora afirma: "El mundo de su infancia [la de la niña protagonista Adriana] tiene que ver bastante con el mío. He plasmado algunos de mis recuerdos y también digo que su vida es de papel, al igual que la mía. [...] Incluso salen algunas de mis experiencias, como la del cuarto oscuro y mi descubrimiento de la luz en la oscuridad, la creación de mi propio universo y de mi propio mundo" (1997: 133-134).

5. A este propósito, se puede leer nuestro artículo (2009: 191-212). 
Al adentrarnos en Paraíso inhabitado, vemos cómo el lenguaje literario va desplegando en la novela un singular estilo tardío que excava en los estratos de la subjetividad en pleno desarrollo de la niña Adriana -la cual crece apegada a su propio mundo imaginativo y estético- para proyectarse sobre la mirada y la voz interior del sujeto de escritura, que se enfrenta al valor de verdad de una lucidez meditativa. Esta última le da la posibilidad de aprehender y descifrar las repercusiones de lo más entrañable y desgarrador de cuanto constituyó y determinó su vida en íntima relación con la exploración de los universos de la creación literaria ${ }^{6}$. Este complejo proceso literario, que se sustenta en un amplio alcance poético como modo de conocimiento de lo recóndito, lo intuido e iniciático, extiende la constante doble perspectiva de enunciación en la textualidad -o sea, la de la niña Adriana y la de la instancia autorial propia del sujeto de escritura-, y la obsesión por el tiempo inseparable de la convergencia de diferentes temporalidades marcadas por la restitución imaginativa y poética de lo que fue así como, necesariamente, de su inexpugnable pérdida.

El primer término clave, que tendrá profundas y variadas repercusiones en los fenómenos de temporalidad a lo largo de la novela, es el de "destiempo" (Matute 2008: 11) inherente a las experiencias de apartamiento, de distanciamiento e incluso de exilio interior. En efecto, Adriana sufre indirectamente no solo de la separación entre sus padres, que ya no se quieren y seguirán cada uno con su vida, sino sobre todo de la frontera discernible entre el mundo de los adultos -es decir, los "Gigantes" tal como los llama la niña- y su propia vida alejada de los centros de interés, de las normas y los tenues afectos de su familia burguesa en la España de los años 1930, que se encamina fatalmente hacia la Guerra Civil. La niña nació, por lo tanto, a "destiempo" en una familia ya desunida, y la singularidad de su personalidad se ve negada por su madre. Adriana encuentra entonces un refugio vital y casi existencial en la ternura, la comprensión y complicidad afectiva que le proporcionan sus cuidadoras, las sirvientas tata María e Isabel, en el espacio privilegiado de transmisión y comunicación que es la cocina. Sin embargo, ese refugio protector y, a la vez, emancipador, Adriana lo encuentra principalmente en la construcción y el descubrimiento de su propio mundo imaginativo y fantástico que se centra en las lecturas ${ }^{7}$ apasionadas de los libros de cuentos:

6. Jordi Gracia y Domingo Ródenas aciertan al señalar que: "La publicación de Paraíso inhabitado (2008) supuso un prodigioso regreso al ámbito de la infancia y las vísperas de la guerra, pero sobre todo a la fragua biográfica de su propia personalidad literaria [la de Ana María Matute]" (2011: 675).

7. Nathalie Prince puntualiza: 'Ce n'est pas l'objet livre en tant que tel qui l'intéresse [l'enfant], mais ce qu'il expose, ce qu'il montre. Le livre n'est pas qu'un livre pour l'enfant. C'est l'occasion d'un acte essentiel, celui de la distance et de la rupture, avec la réalité immédiate au profit de l'élaboration d'un monde poétique et esthétique" (2012: 142-143). 


\begin{abstract}
Si no tenía acceso a sus vidas [las de los "Gigantes"], ellos no la tendrían a la mía: y la mía era infinitamente mejor. Eso me parecía entonces (y aún puedo afirmar ahora, cuando estoy a punto de decir adiós a cuanto me rodea y me rodeó). No puedo permitirme el disimulo ni la falsedad, porque estoy recuperando recuerdos, retazos de un barco de papel arrinconado al fondo de un cajón que nunca tuve valor para abrir. (2008: 13)
\end{abstract}

La confluencia de las miradas de la narradora ya anciana y de la niña que fue $\mathrm{y}$, en cierta medida, sigue siendo en su interioridad al internarse en la densidad del proceso creador del lenguaje literario, intensifica el tono íntimo del sujeto de escritura que desencadena un vasto movimiento de anamnesis en lo más profundo del cual se despliega una refracción de lo desaparecido y, por lo tanto, de la muerte cuya latencia resulta omnipresente en la novela. Al recomponer los fragmentos de los recuerdos, así como las vivencias interiores de su niñez-de ahí la metáfora del "barco de papel arrinconado al fondo de un cajón"-, el sujeto de escritura desea enfrentarse sin máscaras ni posibles amaños a lo más íntimo de su pasado en función de una lucidez crítica, que le introduce en lo insondable de lo incógnito y de las preguntas sin respuesta que recorren toda una vida.

La autobiografía interior ficcionalizada acentúa, pues, los diferentes planos de su profundidad temporal centrándose en el núcleo de los orígenes, que es la infancia, para mostrar cómo la plenitud siempre quebrada y los desgarramientos de sus experiencias más singulares -las de cualquier orden (afectivo, imaginativo y moral)- consiguieron, a lo largo de una vida, potenciar y revelar el poder creador de un lenguaje literario al que el sujeto de escritura empezó a tener acceso y descubrir en su niñez. De modo correlativo, el lenguaje contiene y desvela la aprehensión de tensiones y disensiones diseminadoras de un poder de destrucción contra el cual solo pueden resistir, de manera efímera, la imaginación presente en los juegos, en los libros de cuentos y los espacios recreados por Adriana. La complejidad del lenguaje, sus múltiples temporalidades, los universos que concentra y crea en relación con diversos órdenes de realidad, ya eran intuidos por la niña a través de la literatura infantil y sus posibilidades para iluminar lo que se sitúa más allá de lo visible y permanece inexpresado en los adentros del ser humano:

En los cuentos de Andersen, el gran cómplice de mis primeros años, había aprendido que las flores tenían su lenguaje, sus bailes nocturnos, donde reinaban, y poco después languidecían hasta acabar en la basura. Pero sobre todo, aprendí que existía un lenguaje secreto, un lenguaje al que yo tenía acceso. (2008: 15) 
La cuestión del lenguaje es, en efecto, crucial en la novela -recordemos que se nos dice al principio que Adriana no habla (2008: 15)- y, por lo tanto, conviene destacar las palabras de Eduarda - la tía y amiga cómplice de la niña- que le dice a su hermana, o sea, a la madre de Adriana, que esta última "tendrá otro lenguaje" (2008: 16). Este lenguaje se elabora a partir de la estrecha imbricación entre el mundo de la imaginación inherente a la vida interior de la niña y el modo en que, en función de este último, Adriana descifra e intenta comprender la cruel realidad de los adultos (con las discordias, los conflictos y la violencia exacerbada anterior al estallido de la Guerra Civil), pero también momentos casi maravillosos de amor y belleza (como la escena, por ejemplo, del reencuentro en un restaurante en quiebra entre Eduarda y su amigoamante ruso, Michel). La imbricación entre estos dos universos -el de la imaginación creadora y el de una realidad a menudo situada bajo el signo de la irreductible discordia y venidera pérdida- engendra y potencia los efectos de un fenómeno de anterioridad, cuyas finalidades son complementarias en la poética de la novela.

Se trata, por un lado, de penetrar en lo más hondo de lo experimentado y revelado en ciertos acontecimientos casi epifánicos de la niñez -los cuales perdurarán y evolucionarán en la interioridad del sujeto de escritura a lo largo de la existencia- $y$, por otro, de alcanzar una dimensión extra-temporal que contiene el pasado, el presente y el futuro a fin de significar la imposibilidad de un porvenir capaz de restituir la intensa fuerza de lo vivido y amado y, por eso, siempre apresado por las huellas y los vestigios de lo que fue y jamás pudo plenamente realizarse. Este segundo aspecto clave en la textualidad arroja luz sobre la nostalgia melancólica que impregna la voz de la narradora anciana ${ }^{8}$ en Paraíso inhabitado y desencadena, en la poética del texto, un proceso algo paradójico de disociación que logra atraer y, a la vez, separar entre sí los elementos aparentemente opuestos para internarse en la exploración introspectiva de las formas de subjetividad. Estas configuran, así, las significaciones de una indagación sobre sí misma por parte de la narradora, pero también sobre la naturaleza de la imaginación propia del arte literario y sobre una visión interiorizada del mundo centrándose en la infancia9.

El estilo tardío pone, en cierto modo, a prueba esta indagación, a la vez múltiple y unitiva, mostrando los diferentes rostros de las hendeduras, las

8. Como observa Philippe Merlo-Morat: "[....] la narratrice se cache donc dans les incises, tirets et parenthèses. [...] Cette porosité entre présent de narration et passé montre à quel point la narratrice est en perpétuel équilibre entre les deux périodes qui, dans sa mémoire, parviennent à se confondre" (2017: 192 y 204).

9. Pilar Pedraza señala con pertinencia: "Es una obra enorme [Paraíso inhabitado] con un peso específico que desborda lo estrictamente literario y se desparrama sobre lo primigenio de la escritura, sobre la construcción del mundo y la invención de la psique infantil” (2014: 174). 
ausencias y pérdidas presentes desde el origen, que es el mundo de la niñez, a fin de adentrarse en modos de expresión literaria y de conocimiento poético aptos para adensar todas las hilachas de la materia de lo vivido e íntimamente sentido en el seno de los ya inasequibles posos deslumbrantes de lo que fue y sigue disgregándose en el yo. La voz narrativa consigue, pues, cernir el núcleo germinativo de lo experimentado y descubierto en la infancia situándolo a la luz de las dudas, los desgarros y sentimientos inherentes a la individualidad de los afectos profundos que anidaron en toda una trayectoria vital:

Aquella primera sensación de "nosotros" y "ellos" me persiguió aún durante mucho tiempo; y aún hoy me asalta de cuando en cuando, devolviéndome sombras que acaso no desaparezcan jamás de mi memoria. Tal vez la infancia es más larga que la vida. (2008: 66)

En el estilo tardío de Ana María Matute el origen se relaciona y refleja en el fin y, por lo tanto, en esta secuencia -en la cual la niña y su tía Eduarda, que están acompañadas por los amigos de esta última, son objeto de las miradas extrañadas de los que les rodean- la voz narrativa y meditativa del sujeto de escritura considera la infancia como una especie de horizonte sin término delimitado, así como un círculo casi cerrado: es decir, un período clave imposible de transformarse del todo y cuyo fin no conduce al ingreso a la madurez, sino que acaba en sí mismo con la desaparición de la propia vida. En consecuencia, el sujeto de escritura se encuentra en el centro de gravitación de la textualidad $\mathrm{y}$, por lo tanto, en el punto-encrucijada que le permite repensar, resignificar y extraer, de manera fragmentaria, todo el espesor, la densidad y materialidad de lo descubierto en la infancia para dejar emerger cuanto permanecía todavía soterrado, silenciado e impensado. En efecto, la narradora se sumerge en el auténtico acontecimiento en continuo desarrollo que es la infancia, la cual se abre sobre un perpetuo cuestionamiento interior, a la vez iluminador y lleno de sombras perturbadoras, que resignifica sin cesar los orígenes del yo y arroja luz sobre los fenómenos de extrañeza, de distancia, de separación y peculiaridad que irán excavando sus repercusiones en su personalidad ${ }^{10}$.

El conocimiento y la afirmación de sí misma se unen al fenómeno de la anterioridad indisociable en parte del mundo imaginativo de los libros de cuentos $y$, en otro plano, a la refracción de la muerte, que alcanza su foco central en la

10. La infancia como una especie de imagen de los orígenes es abordada por Suzanne Lafont en el estudio introductorio de su libro colectivo sobre la figura del niño presente en ciertas obras literarias en francés (2012: 10). 
relación amorosa pasional entre Adriana y el muchachito de origen ruso Gavrila. Este último es vecino de la niña y comparte con ella características esenciales: cierta soledad, el distanciamiento con la madre y la necesidad primordial de la presencia del mundo de la imaginación liberadora.

A través de esta relación amorosa, cuyas dimensiones simbólicas y poéticas no cesan de profundizarse en el lenguaje literario, la narradora anciana intensifica la íntima unión entre la imaginación, la lectura -la propia escritora calificó varias veces su niñez de "infancia de papel" - y la escritura como modo, forma y sentido de presencia en el mundo. La figura múltiple de Gavrila -a la vez ángel fatal, en un plano simbólico, y demasiado ansioso de libertad para contentarse con la condición terrestre- encuentra su desdoblamiento fantástico en otra figura: la del Unicornio que se escapa de la litografía del salón de la casa donde vive Adriana, y que la niña contempla en las visiones oníricas que pueblan sus evasiones nocturnas ${ }^{11}$ en el domicilio familiar. La relación apasionada con Gavrila también contiene la experiencia interiorizada de la confluencia de diferentes temporalidades, tal como lo enuncia la narradora cuando intenta nombrar y transmitir lo que sintió al inicio de su relación con el muchachito siempre en busca de un más allá:

\begin{abstract}
Algo que quizá había soñado, o vivido en un tiempo anterior, regresó: nos habíamos conocido antes -o quizá nos íbamos a conocer en un tiempo que aún no había llegado-. Pero sucedía en un presente vivo, casi tan cruel como la luz del mediodía que a veces duele. (2008: 169)
\end{abstract}

Aquí, el pasado relativo a este "tiempo anterior" es el de lo que fue amado y experimentado en el mundo interiorizado de la imaginación, cuyo poder de revelación nace de la lectura de los libros de cuentos ${ }^{12}$ y del animismo infantil. La génesis de los intensos sentimientos amorosos de Adriana por Gavrila proceden y forman ya parte, en su sustancia más intrínseca, de ese mundo de la imaginación -ligado forzosamente a la esperanza y la espera del futuro amor-. Estos sentimientos se proyectan, pues, sobre un tiempo venidero situado, en realidad, más allá y fuera del tiempo, es decir, una especie de realidad irreal que se integra en un horizonte transcendente inalcanzable como símbolo de plenitud

11. En lo que concierne a la imbricación entre el mundo de la imaginación infantil y el de la realidad de los adultos, Maylis Santa-Cruz observa: "Il y a dans Paraíso inhabitado, une hésitation permanente entre deux systèmes de références qui n'est pas sans rappeler Don Quichotte et Adrianaenfant apparaît comme une variation moderne du célèbre chevalier errant, car comme lui, elle est le seul personnage qui vit simultanément dans les deux systèmes" (2014: 559).

12. La lectura de los cuentos -en particular la del Rey Cuervo de los hermanos Grimm- tiene un papel fundamental en los modos de comunicación de la relación amorosa entre Adriana y Gavrila. 
y de realización absoluta de una unión siempre descubierta y sin límites - de ahí las cursivas en el texto original del "íbamos a conocer"-.

Como veremos, ese tiempo más allá del tiempo se traduce en la promesa imposible de cumplir de Gavrila que le repite a Adriana que él volverá a por ella después de su partida-muerte. Sin embargo, ese tiempo del porvenir es un futuro imposible cuya manifestación resulta inasequible y fuera de alcance. Permanece, además, como determinado por los desgarramientos y vestigios del pasado, pero también por la crueldad de un presente avasallador marcado por la incomprensión, la violencia fratricida y la irreductible contingencia de la vida humana. Esta confluencia entre pasado, presente y futuro -que tienen un valor semántico y un estatuto ontológico específicos en el lenguaje literario- se puede relacionar con la concepción de la nostalgia melancólica, que impregna la obra y que es enunciada por la narradora en la última parte de Paraíso inhabitado: "Y por primera vez tuve algo así como la nostalgia precoz, sutil y efímera de lo que aún no había sucedido, pero sucedería. No era tristeza, sólo el reflejo de un viento que esparcía los vilanos de una flor espumosa" (2008: 308).

Esta nostalgia constituye el substrato de la memoria anticipada de un futuro que lleva en potencialidad en él la intensidad de lo más entrañablemente vivido y, a la vez, la fatalidad de su imposible realización venidera y tan solo premonitoria de un desprendimiento y una desaparición irreversibles y terminales. En el estilo tardío de Ana María Matute, la figura de la dualidad excava el envés de lo expresado y de su materia estética indagando a la vez en sus diversas facetas a fin de diseminar y potenciar partículas de una verdad íntima, que dejan trasparentar las huellas y los vestigios de la revelación amorosa al hacer resonar los ecos apagados de la ausencia y del vacío definitivos. Como bien precisa Edward W. Said (2012: 269) en su ensayo crítico sobre el estilo tardío:

\footnotetext{
C'est la prérogative du style tardif que de posséder la faculté de traduire le désenchantement comme le plaisir sans avoir à résoudre la contradiction qu'ils représentent. Ce qui maintient cette tension entre eux, comme des forces de même intensité luttant pour suivre chacune sa direction, c'est la subjectivité de l'auteur, résultant de sa maturité, débarrassée d'hubris et d'emphase, et qui ne rougit pas plus de sa faillibilité que de la modeste assurance que lui ont apportée l'âge et l'exil.
}

En Paraíso inhabitado, el placer o, mejor dicho, el deseo y el desencanto, o la desilusión, son constitutivos de la nostalgia melancólica que encauza el ritmo y las cadencias del lenguaje poético iluminando modos de subjetivación que, al 
concentrar diferentes dimensiones temporales, desvelan la sustancia más íntima de lo conocido y sentido para comprender mejor la hondura y permanencia de sus manifestaciones de orden moral, afectivo y existencial en la vida de la narradora situada ahora en el umbral de la muerte. De hecho, la descripción y posterior reflexión sobre las manos de la lavandera Tomasa -después de que Adriana y Gavrila le ensuciaran, cuando estaban patinando, unas sábanas blancas que la doméstica acababa de tender en la terraza- cobra el valor de una auténtica revelación moral sobre las desigualdades e injusticias sociales, pero también sobre la propia posición de la narradora en la sociedad:

\footnotetext{
Fue la primera vez, acaso, en que me di cuenta de la distancia que nos separaba de las lavanderas, pongo por caso. Yo no estaba en el lado que hubiera querido estar, y las manos rojas, casi despellejadas de Tomasa, adquirieron una importancia insospechada. Fue todo parecido a la luz súbita y fugaz de un relámpago. Pero no desapareció devorado por la noche, sino que aún, ahora mismo, al recordarlo, regresa a mi memoria; y vuelve la inquietud, aunque sea tan inane como soplar hacia una mariposa muerta, atravesada por un alfiler, imposible de volver a la vida. (2008: 320)
}

La visión de los "puños enrojecidos" (2008: 321) de Tomasa -madre soltera con un carácter indómito que será asesinada después del fin de la Guerra Civilse une al agobiante silencio acusador, que inunda la secuencia y todavía, en cierto modo, el recuerdo de la narradora. Este recuerdo adquiere otra significación más aguda y acerada en la muy posterior interpretación crítica del sujeto de escritura, que aclara cómo y por qué se sintió y sigue sintiéndose próxima a los dominados y humildes cuya humanidad y relación con la vida le parecen más sinceras y despojadas de la artificialidad convencional característica de su grupo social y familiar. La imagen de las manos de Tomasa se va, así, transformando en el núcleo de una consideración, e incluso convicción, de índole política respecto a la sociedad muy jerarquizada y llena de desprecio en que le tocó vivir a Adriana, pero también en una suerte de deslumbramiento inaugural de lo que iba a forjar su subjetividad moral profunda.

Es otra experiencia interior del silencio, tras las travesuras de Adriana y Gavrila en la terraza, la que cobra un alcance inaudito y revelador de la hondura y naturaleza de los afectos, que irá sintiendo la narradora en su vida. Aquí, esos afectos, que tienen una profundidad abismal, se descubren en las emociones y los sentimientos que la niña va experimentando en su relación con Gavrila, la cual se encuentra al principio bajo el signo perecedero de una belleza infinita y supuestamente eterna: 
Acaso, aquel silencio, reflexivo y temeroso a partes iguales, nos unía más y más. Qué melancolía me llega a saberlo: si no hubiera sido así, si en aquel momento lo hubiera expulsado de mis recuerdos, mi vida hubiera sido distinta. Probablemente igual de catastrófica, pero, por lo menos, sin su participación. Claro que estas cosas las pienso ahora, cuando todos aquellos hechos permanecen laminados, descoloridos, casi arrancados de las páginas desde donde me habían fascinado. (2008: 322)

El estilo tardío erige la melancolía a la altura de un modo de conocimiento de orden moral, existencial y poético, capaz de esbozar la arqueología de los sentimientos y afectos más íntimos y perennes, que se van desvelando en su propia historicidad en el lenguaje literario. La reflexividad y reciprocidad entre los ámbitos de este último consiguen penetrar en el significado de las formas de subjetividad a la luz de la mise en abyme que ponen en movimiento, aquí, los recuerdos. Se trata, así, de unir los gérmenes virtuales y potenciales de la emoción primigenia transformadora del yo y los estratos de los afectos que oscilaron a lo largo de la vida de la narradora, y ello reconociendo sin cesar la reciprocidad íntima y siempre redescubierta entre lo vivido y lo escrito. Estos recuerdos -mencionados por la narradora- también contienen una figura del olvido que desvela a veces en la conciencia del sujeto impresiones y afecciones que perduran, de modo más o menos virtual, en él y animan interiormente su personalidad y percepción del mundo, así como su relación con los demás.

El adjetivo "catastrófica", que utiliza la narradora para calificar su propia vida, no parece proceder de la idea de desgracia, sino más bien de una especie de búsqueda infinita y sin posible realización verdadera, puesto que permanece abocada a la dispersión y a la precaria reconfiguración incesante de retazos efímeros, deslumbrantes e ilusorios de lo perdido y jamás plenamente cumplido ni vivido a causa del poder sin límites de la disociación antagónica inherente a la vida misma, es decir, también la fatalidad de un destino que ya se desdibuja en el pasado. De hecho, en Paraíso inhabitado la falta de comprensión, de entendimiento y de comunicación real entre los protagonistas resulta casi omnipresente en la narración ${ }^{13}$. Los milagros misteriosos que son la breve relación de la tía Eduarda

13. No es fortuito que esa falta de comprensión también haya afectado la relación de la propia escritora con su madre y, en consecuencia, Mercedes Pons Ballesteros menciona: "Ana María Matute, silenciosa, insegura, ensimismada y encerrada en su mundo, se ha encargado de transferir la comprensión de la que careció en su niñez a sus personajes, sus obras, y a los lectores cumpliendo la promesa que se hizo de niña "yo seré escritora para vengarme de los mayores"' (2009: 2013). No obstante, en Paraíso inhabitado las relaciones de sincero entendimiento entre los personajes casi constituyen una excepción en medio de una realidad en la cual predominan ante todo la discordia y los conflictos. 
con su amigo-amante Michel y sobre todo la de Adriana con Gavrila no pueden llevarse a cabo ni realizarse plenamente en la realidad terrenal y desembocan, pues, en la muerte -la de Michel y la del muchachito-.

Es el filósofo Theodor W. Adorno quien mostró, como sabemos, a mediados de los años 1930, la pertinencia del concepto de "estilo tardío" para denominar las obras del fin de la creación artística y de la vida; y es también él quien se valió del término "catástrofe" para definir esas obras, en particular las del último Beethoven: "Dans l'histoire de l'art, les œuvres tardives sont les catastrophes" (2003: 12). La palabra "catástrofe" se debe entender, aquí, como manifestación de un desenlace doloroso y trágico inherente a la imposibilidad de cualquier síntesis armoniosa e integral. Así pues, el deseo vital de alcanzar una especie de plenitud conciliadora queda siempre subordinado al fracaso y a lo inasequible, que dan lugar necesariamente a la ausencia y al vacío.

No obstante, la particularidad del estilo tardío de Ana María Matute en Paraíso inhabitado consiste en que su escritura profundiza en el complejo y sutil umbral en el cual se oponen y, a la vez, dialogan los arquetipos-símbolos poéticos propios del universo de la imaginación infantil -la figura del Unicornio ${ }^{14}$ así como los libros de cuentos son los mejores ejemplos- y la aprehensión interior de la contingencia y crueldad de la realidad humana, cuyos desgarramientos y ocultaciones va desentrañando la voz meditativa de la narradora anciana enfrentada a la imposibilidad del regreso y de la restitución de lo ya desvanecido. Desde este enfoque, el fenómeno de desprendimiento acentúa en la novela la concatenación de las pérdidas y separaciones -las de Adriana respecto a su padre, a sus hermanos gemelos, Jerónimo y Fabián, y sobre todo a su amor Gavrilapara internarse mejor mediante la dimensión poética y estética relativas a los recuerdos, no solo en la frágil precariedad de lo más intensamente vivido, sino en el reconocimiento de que el único espacio de libertad y belleza se encuentra finalmente en la creación literaria también considerada, en un plano superior, como huella y vestigio de lo que (se) fue. De ahí la constante interpenetración entre lectura, escritura, memoria y desaparición en la poética del texto. Esta especie de simbiosis se abre sobre la significación interiorizada en la voz narrativa de lo existente y vivido ahondando en modos de conocimiento iluminadores del

14. Sobre esta figura mitológica, Néstor Bórquez dice: “Además de las características marcadas del mundo infantil de Adriana y Gavrila, se establece desde el comienzo de la novela la figura de un Unicornio con toda su simbología de pureza e incontaminación a cuestas: figura de un tapiz, sólo los niños pueden ver cuando el fabuloso animal se escapa del cuadro y regresa" (2011: 14). Al igual que el Unicornio, también Gavrila en Paraíso inhabitado se escapa a veces de su casa por las noches y con la muerte del muchachito tampoco el Unicornio podrá ya reaparecer. 
sentido de cuanto se experimenta y descubre en el silencio, la oscuridad y ante el vacío.

Las amplias modalidades de subjetivación inscritas en las formas de expresión con sus gamas rítmicas y cadencias enhebran, pues, los deseos, los sentimientos y emociones fulminantes que recorren los opuestos antagónicos mostrando sin cesar las hendiduras para reforzar un poder de disociación. Este se cierra sobre la irreversible finitud y la desaparición para significar, en otro plano, lo ilusorio de la vida y la necesidad, sin embargo, de seguir creyendo en ella gracias a la imaginación y belleza de lo que se pudo un día sentir.

En los capítulos finales de la novela, no dejan de entrecruzarse la progresiva desaparición del mundo que compartieron Adriana y Gavrila con la evolución fatal de la enfermedad de este último que morirá a causa de una meningitis. En este proceso implacable del fin de un mundo también es la vida de la infancia la que se va quedando atrás y desaparece ${ }^{15}$. La narración agudiza, entonces, la sensación e impresión agobiantes del paso y la premura del tiempo que corre y, por eso, Adriana dice a través de la voz de la narradora al término del capítulo 17: "No se iban a pasar [las fiebres de Gavrila], yo lo sabía. Como sabía, también, que casi, casi, ya no éramos niños" (2008: 342). Al final de la novela, Adriana tiene unos 12 años -al principio algunos episodios clave se remontan a su primera infancia cuando la niña tiene unos 5 años- y ese transcurso del tiempo se acompaña cada vez más con la sensación interior de la naturaleza huidiza y siempre amenazante de un tiempo devorador de lo vivido y de los seres. El constante entrecruzamiento de las redes semánticas, que expanden el conjunto de los efectos e impactos de la desaparición - a través del fin próximo de la infancia, de la muerte venidera de Gavrila y las últimas visitas, por parte de Adriana, a los espacios compartidos por ella y el muchachito a fin de despedirse para siempre de los lugares, los objetos y testimonios materiales de su amor-, refuerza poderosamente la progresiva invasión de la pérdida y del vacío. Después de la muerte de Gavrila, Adriana se queda, en cierto modo, sin mundo: en efecto, el de la infancia ya no existe en la realidad y el de los adultos se encuentra anegado

15. Cabe tomar en cuenta las palabras de Anne Paoli sobre el fin de la infancia en la obra de Ana María Matute: "Dans ce sens, la majeure partie de ses romans, nouvelles et contes marque un tracé initiatique du jeune héros ou de la jeune héroïne, tout en soulignant ce point d'inflexion si fragile, si ténu, qu'est la limite entre la mort de l'enfance et le passage à l'âge adulte. Le caractère irrémédiable de ce franchissement colore ses textes d'une infinie nostalgie. Paraíso inhabitado répond de manière magistrale à la description si délicate, si difficilement perceptible parfois de cet entre-deux douloureux et inéluctable. Mais là encore, le roman pourrait être considéré comme le point d'orgue d'un chemin narratif particulièrement nourri en la matière" (2017: 35). 
en la violencia y discordia. La chica irá a vivir con Eduarda durante los tres años de la Guerra Civil en la propiedad rural de su tía que se llama "las ruinas", como si ese nombre designara precisamente un espacio apartado del mundo y fuera simbólico de los vestigios del pasado.

Al final de Paraíso inhabitado, el vacío contamina y se repercute sobre otros espacios y lugares de vida que hacen ahora solo visible la ausencia. La narradora descifra y comprende entonces en su interioridad lo que el tiempo disociador y la realidad humana antagónica hicieron desaparecer para siempre; y, de este modo, Adriana enuncia en la antigua habitación de sus hermanos en la casa familiar: "ahora veía el vaciado, el hueco, la huella que Jerónimo y Fabián habían dejado en el cuarto" (2008: 351). El avasallador despliegue de la ausencia conduce, al término del capítulo 18, a que Adriana experimente, por primera vez, una radical desposesión cuando se entera de que Gavrila se está muriendo. Adriana siente profundamente una especie de vaciamiento interior como si todo fluyera de ella y la dejara en la nada: "Todo huía de mí. [...] Fue la primera vez que me morí" (2008: 360).

El lenguaje poético anuda las redes del proceso de desaparición para concentrar una proyección interiorizada en el núcleo de la subjetividad de la niña, y ello a la luz de lo que el universo de la creación literaria va mostrando y excavando: a saber, el final trágico de una etapa crucial de la vida de Adriana -su infancia- cuya culminación catastrófica reside en la muerte de Gavrila. Aunque este último no cesó de repetirle a Adriana que volvería a por ella, la desaparición definitiva del muchachito, que se une en la cosmovisión imaginativa de la niña a la no-aparición del Unicornio antes admirado, reafirma y resignifica el poder irremediable de la disociación y del arrancamiento. Este último deja atrás para siempre -en los recuerdos y en el olvido que contiene la memoria- el mundo creativo y sin cesar reinventado de la imaginación propio de la infancia aboliendo a la vez, de manera algo paradójica, la noción de futuro como horizonte de espera y de esperanza alentadoras ${ }^{16}$.

Tras la muerte de su amor fatal Gavrila, Adriana se sobrevive a sí misma -pese a que el dolor se irá convirtiendo cada vez más en sombra-, lo que

16. El filósofo Claude Romano precisa sobre la noción de futuro: "Seul le possible est vraiment inoubliable. C'est pourquoi la mémoire n'a pas trait à des faits, mais elle germine au cœur des événements pour autant qu'ils portent en germe, bien que passés, un futur irréductible. [...] ce dont l'advenant a mémoire, c'est ce qui, du 'passé', possède encore et toujours pour lui un avenir : l'événement même" (2012: 207). En Paraíso inhabitado, es ante todo la imposibilidad de la plena realización del propio acontecimiento o événement - es decir, lo más intensamente vivido en la relación amorosa entre Adriana y Gavrila-, la que lo separa de un futuro inconcebible y situado en un más allá inalcanzable simbolizado por la imposibilidad del regreso del muchachito después de su muerte. 
intensifica en los sustratos de la narración la presencia de la nostalgia melancólica indisociable de la memoria anticipada de un futuro sustentado por las añoranzas, los desgarramientos, las pérdidas y sobre todo el vacío, inherentes a la plenitud deshecha de lo vivido. La fuerza de imantación de esa plenitud deshecha y siempre quebrada arroja luz sobre el imposible regreso a lo descubierto y ya solo sometido al desvanecimiento de cuanto Adriana más amó, poniendo de relieve, en un segundo plano, el engaño y la crueldad presentes en la realidad del mundo de los adultos:

Y me dije que aquello que todo el mundo llamaba años, o tiempo, y yo no sabía cómo llamar,
era un dragón devorador, un lobo, una hiena -otra vez se repetían los cromos del Album
Nestlé-. Y me atemorizaba el mundo que estaba esperándome con las fauces abiertas puertas
afuera, el mundo atroz del que oía decir que estaba lleno de malas gentes incendiarias, malas
gentes que apaleaban a criaturas tan dulces y entrañables como Teo [...]. (2008: 288)

A partir de la muerte de Gavrila, Adriana pierde la inocencia, la ilusión y el deseo, y reconsidera su relación con los demás. La niña se confronta a una doble desilusión dramática, o sea, una especie de doble negación bastante devastadora: por un lado, su rechazo protector de la crueldad despiadada del mundo de los adultos $\mathrm{y}$, por otro, la terrible sensación interior de engaño amargo al constatar cada vez más la imposibilidad del regreso de Gavrila. Ya no cabe, pues, ninguna esperanza de restitución de lo vivido y, por eso, la permanente refracción de la muerte da lugar a que la voz narrativa se adentre en los signos, las figuras e imágenes de lo sepultado. Antes de dejar para siempre los lugares y espacios compartidos, de manera íntima, con Gavrila, Adriana revive en su interioridad lo que se reveló y descubrió con el muchachito a través de cuanto dejaba emerger y expresar en ambos la lectura apasionada de los libros de cuentos:

\footnotetext{
Revivía en mi memoria la lectura del cuento, de bruces sobre la alfombra de rombos con el libro entre los dos, su cabeza rozando la mía pasando las hojas a un tiempo, con sintonía mágica. [...] Estas imágenes [las del cuento La Reina de las Nieves] se agolpaban en mi mente, y cerraba los ojos. Todas coincidían con una realidad recién descubierta. Como un calco de imágenes soñadas sobre imágenes reales. (2008: 379)
}

La voz narrativa convierte nuevamente el espacio textual en un palimpsesto para dejar aflorar y cristalizar lo que Adriana y Gavrila vivieron y sintieron en su lectura compartida; $y$, por lo tanto, sumergiéndose en esta última, la niña intenta 
recobrar la fuerza de imantación de la presencia y casi del ser del muchachito como si le acompañara y dialogara silenciosamente con él en el más allá. De ahí la absorbente impresión de alcanzar una suerte de tercera dimensión situada más allá de lo real y lo soñado, y en la cual el sujeto de escritura trata de iluminar las semillas y fulgurantes emociones de un amor que también se iba revelando en lo que vivían los personajes de los cuentos. Por parte de Gavrila, también esa comunicación con Adriana intenta sobrepasar la frontera de la muerte. En efecto, conviene observar un hecho nada anodino en la narración: cuando la madre de Gavrila, tras la muerte de su hijo, le ofrece a Adriana el libro del cuento del Rey Cuervo - personaje con el que se identificaba el muchachito-, la niña se da cuenta de que las páginas del último capítulo -que ella y él nunca llegaron a leer- han sido arrancadas (2008: 375). Como si Gavrila se hubiera llevado con él en la muerte esas páginas finales que jamás llegaron ni llegarán a leer ella y él, pero que contienen a la vez parte de la esencia primordial de la relación amorosa entre ambos y, por lo tanto, parte de la presencia y del amor por Adriana para siempre. Por eso, cuando la niña se percata de la ausencia del capítulo final del cuento, la voz narrativa evoca la imagen y presencia del Unicornio:

Cuando lo abrí, vi que faltaba el último capítulo. Alguien -no sé quién ni por qué- lo había arrancado.

Miré ansiosamente el cuadro: el Unicornio estaba allí, pero noté su jadeo, casi me rozó su agitada respiración, el temblor de sus patas, tras una fatigosa carrera, seguramente había hecho un penoso recorrido. Pero ahora estaba allí. (2008: 375)

Sin embargo, esta especie de tercera dimensión supra-real -más allá de la realidad, de lo soñado e imaginado- emana de la interioridad más profunda del sujeto de escritura, que solo la está vislumbrando y descubriendo de modo muy tenue; y también se desvanece y se vuelve cada vez más oscura al enfrentarse a la radicalidad de su propia imposibilidad y, en consecuencia, a la realidad inexpugnable del vacío: "Nada quedaba de lo nuestro, lo habían quemado. [...] ¿Cómo era posible aquella desaparición, cómo sentirme ante nuestro mundo sepultado? [...] Como si no hubieran existido" (2008: 382).

La poeticidad de la escritura de Ana María Matute en Paraíso inhabitado concibe un singular estilo tardío que, al unir sus componentes extremos en particular, la infinita belleza de lo más amado y su final e irreductible desaparición inconcebible-, condensa a la vez todas las experiencias perennes y los afectos más hondos de una existencia; y ello, multiplicando las 
interacciones entre la penetrante proyección en la lectura, la escritura como proceso interiorizado del desentrañamiento de las formas de subjetividad profunda y el reconocimiento del ser íntimo. La novela no se adentra en la vejez como decrepitud ni extrañamiento hacia la vida ya distante, sino en la plena, lúcida y última fase de la madurez despojada de toda concesión y que solo debe enfrentarse al valor de verdad de lo vivido y sentido por el sujeto de escritura. La obra ilumina, así, desde dentro la hondura de la palpitación de las sensaciones nacientes y del descubrimiento de sí mismo de una niña, cuya interioridad esencial sigue poblando los estratos de la subjetividad así como los recuerdos de un sujeto de escritura. Este último se despide para siempre de cualquier posibilidad de regreso - o renacimiento- a la potencia deslumbradora y originaria de lo otrora experimentado y revelado en el anhelado "paraíso" siempre revivido, truncado y soñado de la infancia. La gran fuerza de la escritura de Ana María Matute consiste, pues, en desentrañar los entresijos más sensibles de ese anhelado "paraíso" esculpiendo, a la vez, sus vestigios en cuanto depósitos, desgarramientos y figuras del tiempo como única verdad del resplandor de la invención y de las tinieblas de la realidad que se redescubren y perecen en el universo, las voces y los silencios de la creación literaria.

\section{Bibliografía}

ADORNO, T. W. (2003). Moments musicaux. Genève: Contrechamps. Traducción francesa de M. Kaltenecker.

BÓRQUEZ, N. (2011). "Memoria, infancia y guerra civil: el mundo narrativo de Ana María Matute". Olivar 16: 159-177.

CAÑETE OCHOA, J. et al. (Coords.) (2011). La palabra mágica de Ana María Matute. Premio Cervantes 2010. Alcalá de Henares: Universidad de Alcalá. GAZARIAN-GAUTIER, M.-L. (1997). Ana María Matute. La voz del silencio. Madrid: Espasa Calpe.

GRACIA, J. y RÓDENAS, D. (2011). Historia de la literatura española. Derrota y restitución de la modernidad (1939-2010). Barcelona: Crítica.

LAFONT, S. (2012). "Avant-propos" en Récits et dispositifs d'enfance (XIXèXXIè siècles). (Coord. L. Lafont). Montpellier: Presses universitaires de la Méditerranée: 7-26.

LLORED, Y. (2009). "Escritura, memoria y olvido en Telón de boca de Juan Goytisolo" en Pesquisas en la obra de Juan Goytisolo. (Coords. B. Adriaensen y M. Kunz). Amsterdam-New York: Rodopi-Brill: 191-212. 
MATUTE, A. M. (1998). En el bosque. Madrid: Real Academia Española.

MATUTE, A. M. (2008). Paraíso inhabitado. Barcelona: Destino.

MATUTE, A. M. (2014). Luciérnagas. (Ed. M. L. Sotelo Vázquez). Madrid: Cátedra.

MATUTE, A. M. (2014). Demonios familiares. Barcelona: Planeta.

MERLO-MORAT, P. (2017). Ana María Matute. Paraíso inhabitado. Neuilly: Atlande.

PAOLI, A. (2017). "Paraiso inhabitado: miroir d'une trajectoire narrative aux multiples facettes" en Vers le paradis inhabité d'Ana María Mature. (Coords. N. Noyaret e I. Prat). Binges: Orbis Tertius: 13-43.

PEDRAZA, P. (2014). "Ana María Matute o las ficciones de la pena". Claves de Razón Práctica 236: 166-175.

PONS BALLESTEROS, M. (2009). "El paraíso inhabitado de Ana María Matute: entre la realidad y la fantasía". Tavira 25: 209-223.

PRINCE, N. (2012). "Lectures pour l'enfant, lectures de l'enfant" en Enfance et littérature. (Coord. V. Gély). París: SFLGC: 129-152.

ROMANO, C. (2012). L'événement et le temps. París: PUF.

SAID, E. W. (2012). Du style tardif. Arles: Actes Sud. Traducción francesa de M.-V. Tran Van Khai.

SANTA-CRUZ, M. (2014). "Un autre monde est-il possible ? Paraíso inhabitado d'Ana María Matute”. Bulletin Hispanique 116 (2): 549-561. 